\title{
Clinical and functional evaluation of patients with rectocele and mucosal prolapse treated with transanal repair of rectocele and rectal mucosectomy with a single circular stapler (TRREMS)
}

\author{
V. M. Leal · F. S. P. Regadas • \\ S. M. M. Regadas • L. R. Veras
}

Received: 12 May 2010/Accepted: 17 September 2010/Published online: 19 October 2010

(C) The Author(s) 2010. This article is published with open access at Springerlink.com

\begin{abstract}
Background The aim of the present study was to make a preoperative and postoperative clinical and functional evaluation of patients who underwent transanal repair of rectocele and rectal mucosectomy with a single circular stapler (TRREMS procedure) as treatment for obstructed defecation syndrome (ODS) caused by rectocele and rectal mucosal prolapse (RMP).

Methods This prospective study included 35 female patients, 34 multiparous and one nulliparous, with an average age of 47.5 years (range 31-67 years), rectocele grade II $(n=13 / 37.1 \%)$ or grade III $(n=22 / 62.9 \%)$, associated with RMP. The study parameters included ODS, constipation, functional continence scores and pre- and postoperative cinedefecographic findings.

Results The average preoperative ODS score, the constipation score and the functional continence score were significantly reduced after surgery from 10.63 to 2.91 $(p=0.001), 15.23$ to $4.46(p=0.001)$ and 2.77 to 1.71 ( $p=0.001)$, respectively. Between the first and the eighth postoperative day, the average visual analog scale pain score fell from 5.23 to $1.20(p=0.001)$. Satisfaction with treatment outcome was $79.97,86.54,87.65$ and 88.06 at $1,3,6$
\end{abstract}

V. M. Leal

Hospital Getúlio Vargas,

Federal University of Piauí, Teresina, Brazil

F. S. P. Regadas · S. M. M. Regadas · L. R. Veras

Department of Surgery, Medical School,

Federal University of Ceará, Fortaleza, Brazil

V. M. Leal ( ()

Rua Tabelião José Basílio, 1248, Bairro de Fátima,

Teresina, Piauí 64048-190, Brazil

e-mail: vilmarmoura@hotmail.com and 12 months, respectively. Cinedefecography revealed average reductions in rectocele size from $19.23 \pm 8.84 \mathrm{~mm}$ (3-42) to $6.68 \pm 3.65 \mathrm{~mm}$ (range 0-7) at rest and from $34.89 \pm 12.30 \mathrm{~mm}$ (range 20-70) to $10.94 \pm 5.97 \mathrm{~mm}$ (range 0-25) during evacuation (both $P=0.001$ ).

Conclusion The TRREMS procedure is a safe and efficient technique associated with satisfactory anatomic and functional results and with a low incidence of postoperative pain and complications.

Keywords Constipation - Obstructed defecation syndrome $\cdot$ Rectocele $\cdot$ Rectal mucosal prolapse

\section{Introduction}

Rectocele is observed in $20.0-80.0 \%$ of female patients referred to treatment for pelvic floor disorders [1]. Anorectal symptoms of rectocele include constipation, sensation of incomplete evacuation, rectal bleeding (20-60\% of patients), rectal pain (12-70\% of patients), defecation aided by anal, vaginal, perianal or perineal digitation, fecal incontinence, urgency and tenesmus [1]. In addition, some patients complain of gynecologic conditions such as dyspareunia, painful vaginal mass and sexual dysfunction [1]. Rectocele may be treated conservatively or with a range of surgical techniques by transvaginal or perineal access (favored by gynecologists) or transanal access (favored by coloproctologists) [2, 3].

In a study on the concept of rectovaginal pressure gradient (in which the rectovaginal septum plays a less important role), Shafik et al. [4] pointed out that many patients with a prior vaginal delivery did not develop rectocele. On the contrary, researchers increasingly recognize the importance of evacuation disorders in the etiology of 
rectocele, especially in light of recent improvements in scanning methods and functional tests, suggesting that colorectal surgeons have a greater contribution to make to the treatment of rectocele using staplers and transanal access. With the introduction of circular staplers in the treatment of rectal mucosal prolapse [5] and hemorrhoids [6], new possibilities have emerged for the treatment of dystopias of the middle and posterior pelvic floor. Stapled transanal rectal resection (STARR), which involves a double-stapling technique, has become widely accepted and has been tested in multicenter studies with good results [7-17], proving it to be safe when performed by surgeons skilled in the use of staplers [10, 18]. In multicenter studies, Renzi et al. [19] and Lenisa et al. [20] used the STARR procedure with a new stapler design marketed under the name Contour Transtar ${ }^{\mathrm{TM}}$. In Brazil, Regadas et al. [21] developed a procedure for the treatment of rectocele using a mechanical circular stapler: transanal repair of rectocele and rectal mucosectomy with a single circular stapler (TRREMS). The aim of the present study was to make a preoperative and postoperative clinical and functional evaluation of patients who underwent the TRREMS procedure for obstructed defecation syndrome (ODS) caused by rectocele and rectal mucosal prolapse (RMP).

\section{Materials and methods}

This prospective and analytical study included 35 female patients aged $47.5 \pm 10.83$ years (range 31-67 years) attending the outpatient coloproctology service at Hospital Getúlio Vargas (Teresina, Brazil) between March 2006 and April 2008. The patients were clinically diagnosed with ODS caused by rectocele grade II $(n=13 / 37.1 \%)$ (the anterior rectal wall and posterior vaginal wall did not protrude beyond the vaginal opening) or grade III ( $n=22$ / $62.9 \%$ ) (the anterior rectal wall and posterior vaginal wall protruded beyond the vaginal opening) associated with anoscopically confirmed RMP with indications for surgery (Table 1) as all of them had been clinically managed (high fiber diet/laxatives) for a period of at least 4 months. One patient was nulliparous $(2.85 \%)$; the remainder had had an average of $4.59 \pm 2.34$ (range 2-10) deliveries. Twentytwo patients $(64.7 \%)$ had had $2.59 \pm 1.40$ (range 1-5) normal hospital deliveries, 17 patients $(48.6 \%)$ had had $4.65 \pm 3.14$ (range 1-10) normal home deliveries and 12 patients $(35.3 \%)$ had had $1.67 \pm 0.89$ (range $1-4)$ cesarean sections. Six patients $(17.1 \%)$ had undergone perineoplasty, while 7 (19.9\%) had had hysterectomy (one vaginal). Patients with anismus at cinedefecography (no relaxation of the puborectal muscle during evacuation) and other compartment prolapses or fecal incontinence (score $>10,0$ ) were excluded from this study. All participants gave their informed written consent (to surgical and nonsurgical procedures) prior to enrollment in the study.

The study parameters included the modified obstructed defecation score [19], the validated Cleveland Clinic constipation score [22], the functional continence index [23] prior to and 3 months after surgery, the visual analog scale (VAS) pain score [24] on the 1st and 8th postoperative day, satisfaction with functional outcomes (VAS) at 1, 3, 6 and 12 months after surgery. All patients were submitted to gynecologic, rectosigmoidoscopic, cinedefecographic and proctologic examinations prior to and 3 months after surgery, as well as clinical and proctologic examinations upon follow-up visits.

\section{Cinedefecography}

Six measurements were taken during cinedefecography [25]: (a) the angle between the anal canal axis and the posterior rectal wall (ARA) at rest and during evacuation, (b) the size $(\mathrm{mm})$ of the herniation, i.e. the greatest distance between the median longitudinal axis of the anal canal and the anterior rectal wall projecting toward the vaginal lumen at rest and during evacuation (REC), (c) difference in distance (mm) between the pubococcygeal line and the anorectal junction (ARJ) at rest and during evacuation, corresponding to the perineal descent (PD), (d) the distance (mm) between the pubic symphysis and the impression of the puborectal muscle (PRM) on the posterior rectal wall, corresponding to the length of the PRM at rest and during straining and evacuation, (e) the distance $(\mathrm{mm})$ between the anorectal junction and the anal border, corresponding to the length of the anal canal (ACL) and (f) the difference between the volume of contrast administered and the volume evacuated, corresponding to the percentage of residue retained after evacuation (RES).

Surgical technique [21]

A circular anal dilator was introduced into the anal canal and attached to the perineal skin. The visualization of the

Table 1 Age of patients and clinically established rectocele grade

\begin{tabular}{llllll}
\hline & Age & Rectocele & & \\
\cline { 2 - 6 } & & Grade I & Grade II & Grade III & Total \\
\hline Patients & $47.5 \pm 10.83$ & 0 & $13(37.1 \%)$ & $22(62.9 \%)$ & $35(100.0 \%)$ \\
\hline
\end{tabular}




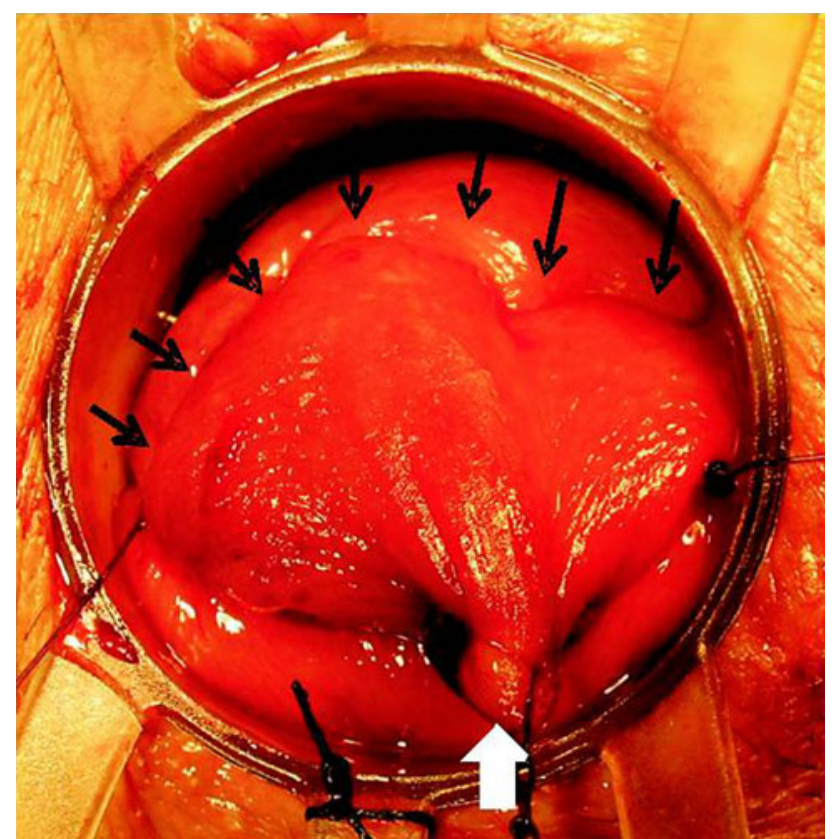

Fig. 1 A stitch is positioned at the apex of the everted rectocele (white arrow), and a mattress running suture is applied at the base of the rectocele (black arrows)

rectocele was aided by digital eversion through the vagina. After retracting the posterior vaginal wall with a forceps, a repair thread was stitched to the apex of the everted rectocele, while the lower extremity (involving all the layers of the rectal wall) was secured with a running horizontal mattress suture (Fig. 1). The rectocele wall was then resected with an electric scalpel leaving the stitched borders visible (Fig. 2). Subsequently, a circular purse-string suture involving mucosa and submucosa was placed close to the suture of the rectocele on the anterior rectal wall and two centimeters from the dentate line along the remainder of the wall. A 34-mm CEA circular stapler (Covidien, New Haven, CT, USA) was introduced and, with the mucosalsubmucosal purse-string suture aligned to the stapler's center rod (Fig. 3), the stapler was fired resecting simultaneously the anterior wall of the anorectal junction and the mucosa and submucosa of the remainder of the circumference. Finally, the staple line was inspected for integrity and hemostasis (Fig. 4). Cefoxetin (1 g) and metronidazol $(500 \mathrm{mg}$ ) were used for prophylaxis, and monobasic and dibasic sodium phosphate $\left(130 \mathrm{ml}\right.$ Fleet-enema $\left.{ }^{\circledR}\right)$ were used for the enema.

\section{Statistical analysis (SPSS $10^{\circledR}$ )}

Findings were submitted to analysis with the Wilcoxon nonparametric test. The level of statistical significance was set at $P<0.05$.

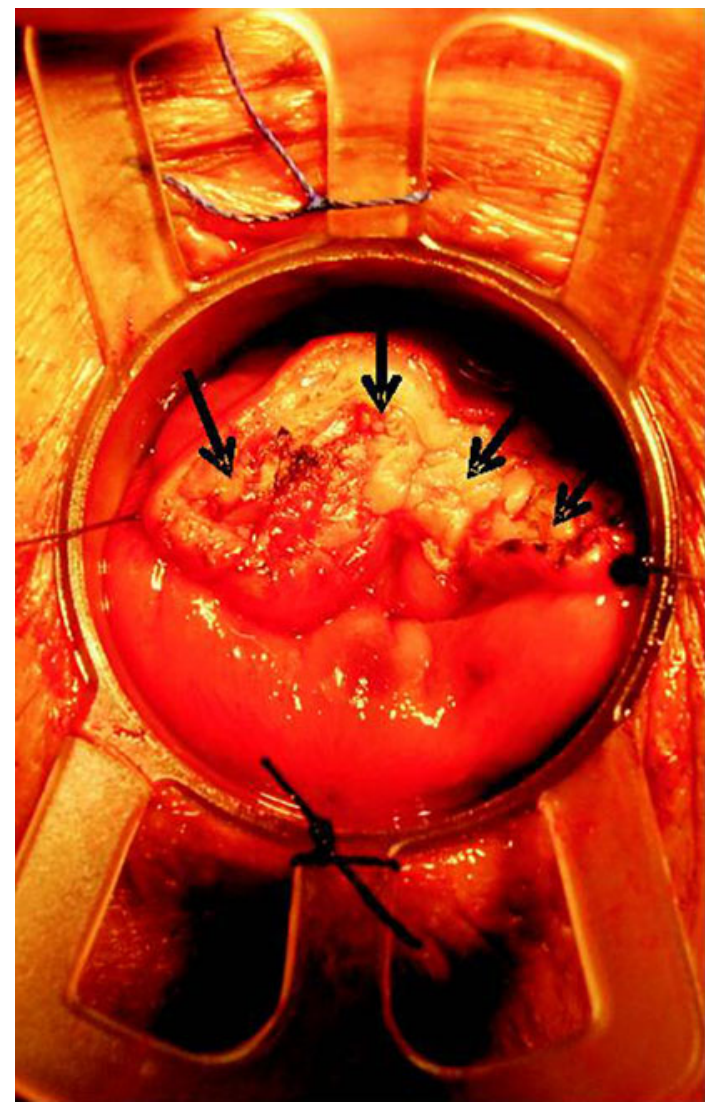

Fig. 2 The rectocele wall was then resected with an electric scalpel leaving the stitched borders visible (black arrows)

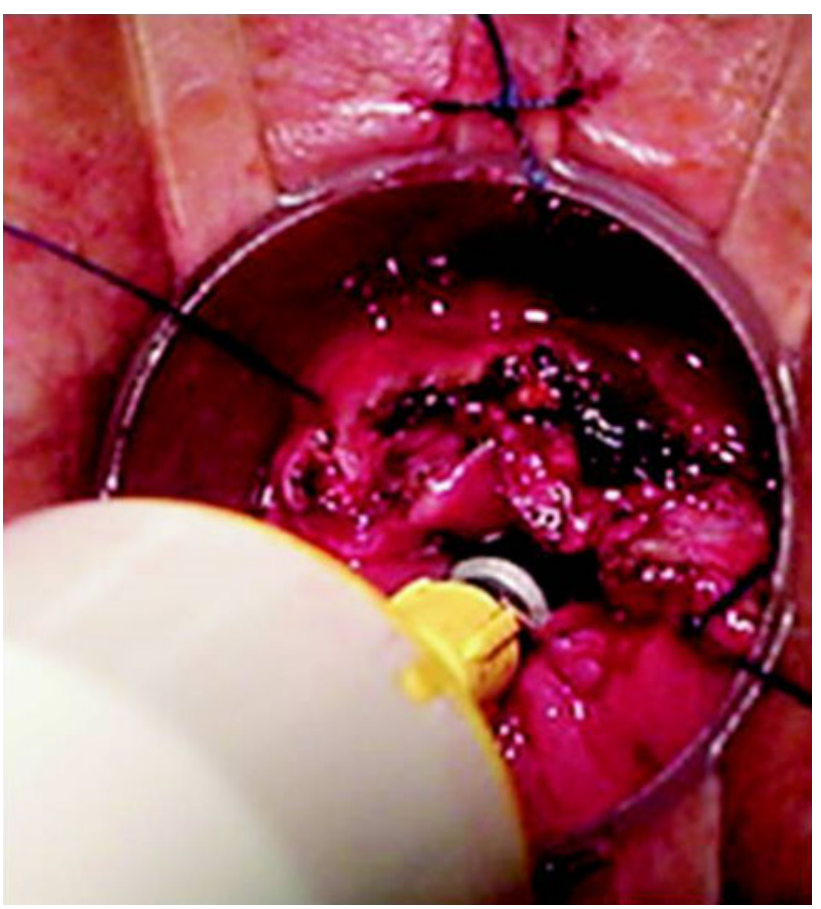

Fig. 3 The mucosa-submucosa purse-string suture is tied around the stapler center rod 


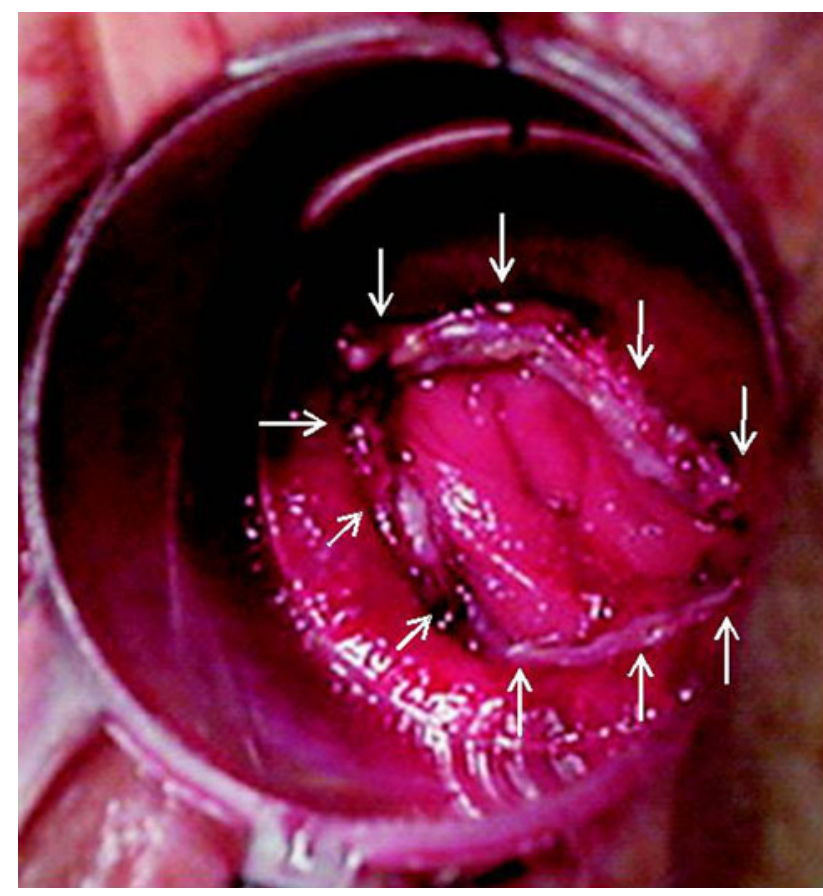

Fig. 4 The stapler is fired and removed, leaving a circular stapled suture (white arrows)

\section{Results}

Eight patients $(22.85 \%)$ presented mild bleeding from the stapled suture line controlled with a single suture. The average duration of surgery was $45 \pm 8.77$ min (range 33-70 min). All patients were hospitalized for $24 \mathrm{~h}$ with no early complications. Five patients (14.28\%) experienced late postoperative complications, including three cases $(8.57 \%)$ of moderate stenosis observed at 1-month followup, two of which $(5.72 \%)$ resolved spontaneously (the third patient developed annular stenosis of the mucosa and was submitted to stricturotomy). One year after surgery, one patient developed a $3.0-\mathrm{cm}$ granuloma on the suture line, which was resected without complications. Another patient experienced intense pelvic pain, proctalgia, hypogastralgia, sensation of pelvic heaviness and dyspareunia. CT and MRI scans revealed thickening of the anterior rectouterine pouch due to endometriosis. On the average, patients were followed for $18 \pm 7.5$ months (range 10-36 months). The average ODS score decreased from 10.63 (range 7-17) to 2.91 (range $1-6)(p=0.001)$. Likewise, the average obstructed defecation score (straining, sensation of incomplete evacuation, use of enemas or laxatives and digital evacuation) was significantly reduced after surgery (Table 2 ). The average functional continence score fell from 2.77 to 1.71 $(p=0.001)$, and the average validated Wexner constipation score decreased from 15.23 (range 8-23) to 4.46 (range $1-12)(p=0.001)$ after surgery. On the first postoperative day, the average pain score was 5.2 compared to 1.2 on the eighth day, and 3 patients (8.5\%) complained of anal discomfort and fecal urgency for 3 weeks. The average levels of satisfaction at 1, 3, 6 and 12 months following surgery were 79.9 (range 52-92), 86.5 (range 37-95), 87.6 (range 26-95) and 88.0 (range 20-97), respectively. Upon cinedefecography, preoperative and postoperative rectocele size differed significantly between rest $(p=0.001)$ (Table 3) and straining with regard to the anorectal angle $(p=0.033)$, anal canal length $(p=0.028)$, puborectal muscle length $(p=0.001)$ and rectocele size $(p=0.001)$ (Table 4).

\section{Discussion}

Growing familiarity with surgical staplers over the past few years has spurred research, in some cases multicenter studies, based on the STARR procedure [11-17]. However, a number of complications have been reported [18]. Therefore, to optimize the technique, some authors have proposed modifying the stapler $[19,20]$ or using a single stapler, as proposed by Regadas et al. [21]. The present study evaluated 35 female patients with ODS caused by

Table 2 Preoperative and postoperative obstructed evacuation syndrome scores

\begin{tabular}{|c|c|c|c|c|c|}
\hline \multirow[t]{2}{*}{ Symptoms } & \multicolumn{5}{|l|}{ Frequency } \\
\hline & Never $(0)$ & Rarely (1) & Occasionally (2) & Usually (3) & Always (4) \\
\hline \multirow[t]{2}{*}{ Excessive straining } & Pre 0 & $1(2.9 \%)$ & $1(2.9 \%)$ & $18(51.4 \%)$ & $15(42.8 \%)$ \\
\hline & Post $1(2.9 \%)$ & $6(17.1 \%)$ & $27(77.1)$ & $1(2.9 \%)$ & 0 \\
\hline \multirow[t]{2}{*}{ Sensation of incomplete evacuation } & Pre 0 & $1(2.9 \%)$ & $12(42.8 \%)$ & $15(42.8 \%)$ & $7(20 \%)$ \\
\hline & Post 0 & $32(91.4 \%)$ & $3(8.6 \%)$ & 0 & 0 \\
\hline \multirow[t]{2}{*}{ Use of enemas or laxatives } & Pre $14(40 \%)$ & $6(17.1 \%)$ & $9(25.8 \%)$ & $6(17.1 \%)$ & 0 \\
\hline & Post $34(97.1 \%)$ & $1(2.9 \%)$ & 0 & 0 & 0 \\
\hline \multirow[t]{2}{*}{ Vaginal, perineal or anal digitation } & Pre 0 & 0 & $4(11.4 \%)$ & $18(51.4 \%)$ & $13(37.2)$ \\
\hline & Post $35(100 \%)$ & 0 & 0 & 0 & 0 \\
\hline
\end{tabular}

Never: 0; Rarely: $<1$ /month; Occasionally: $<1 /$ week and $\geq 1$ /month; Usually: $<1 /$ day and $\geq 1 /$ week; Always $\geq 1$ day 
Table 3 Preoperative and postoperative average rectocele size on cinedefecography at rest

\begin{tabular}{|c|c|c|c|c|c|c|c|c|c|c|}
\hline & \multicolumn{2}{|l|}{ ARA } & \multicolumn{2}{|l|}{$\mathrm{ACL}$} & \multicolumn{2}{|l|}{ ARJ } & \multicolumn{2}{|c|}{$\mathrm{REC}^{*}$} & \multicolumn{2}{|l|}{ PRM } \\
\hline & Pre & Post & Pre & Post & Pre & Post & Pre & Post & Pre & Post \\
\hline \multirow[t]{2}{*}{ Average } & 99.69 & & 29.57 & & 52.69 & & 19.23 & & 71.14 & \\
\hline & 111.77 & & 31.00 & & 56.80 & & 6.68 & & 71.03 & \\
\hline \multirow[t]{2}{*}{ SD } & 21.19 & 19.60 & 15.87 & & 22.29 & & 8.84 & & 18.37 & \\
\hline & & & 13.89 & & 19.63 & & 3.65 & & 14.36 & \\
\hline Minimum & 65 & 73 & 15 & 7 & 20 & 23 & 3 & 0 & 35 & 36 \\
\hline Maximum & 141 & 160 & 75 & 67 & 113 & 94 & 42 & 7 & 120 & 105 \\
\hline
\end{tabular}

$A R A$ anorectal angle; $A C L$ anal canal length; $A R J$ anorectal junction at rest; $R E C$ rectocele; $P R M$ puborectal muscle

* Wilcoxon $p=0.001$

Table 4 Preoperative and postoperative average anorectocele size on cinedefecography during straining

\begin{tabular}{|c|c|c|c|c|c|c|c|c|c|c|c|c|c|c|}
\hline & \multicolumn{2}{|l|}{ ARA* } & \multicolumn{2}{|c|}{ ACL** } & \multicolumn{2}{|l|}{ ARJ } & \multicolumn{2}{|c|}{ REC*** } & \multicolumn{2}{|l|}{ RES } & \multicolumn{2}{|c|}{ PRM*** } & \multicolumn{2}{|l|}{ DES } \\
\hline & Pre & Post & Pre & Post & Pre & Post & Pre & Post & Pre & Post & Pre & Post & Pre & Post \\
\hline \multirow[t]{2}{*}{ Average } & 126.43 & & 19.14 & & 81.06 & & 34.89 & 10.94 & 25.14 & 22.00 & 92.69 & 91.57 & 28.37 & 23.91 \\
\hline & 135.03 & & 21.40 & & 80.97 & & & & & & & & & \\
\hline SD & 22.16 & 16.07 & 10.69 & 9.43 & 21.18 & 19.35 & 12.30 & 5.97 & 11.66 & 10.30 & 23.19 & 17.99 & 13.96 & 12.22 \\
\hline Minimum & 90 & 95 & 7 & 8 & 45 & 46 & 20 & 0 & 5 & 5 & 45 & 45 & 0 & 0 \\
\hline Maximum & 160 & 170 & 47 & 45 & 123 & 118 & 70 & 25 & 50 & 40 & 132 & 127 & 64 & 50 \\
\hline
\end{tabular}

$A R A$ anorectal angle; $A C L$ anal canal length; $A R J$ anorectal junction during straining; $R E C$ rectocele; $R E S$ residue; $P R M$ puborectal muscle; $D E S$ descensus

* Wilcoxon $p=0.033$

** Wilcoxon $p=0.028$

*** Wilcoxon $p=0.001$

rectocele and internal rectal mucosal prolapse. The patients were diagnosed by clinical, gynecologic, proctologic and cinedefecographic examination and underwent the TRREMS procedure. Preoperative and postoperative constipation and defecation scores were assigned, and patient satisfaction with surgical results, pain level and sexual function was measured with the VAS. The average age of our study population $(47.5 \pm 10.83$ years $)$ was similar to that of populations in other recently published studies evaluating the use of staplers in surgical correction of rectocele $[11,16]$. Likewise, the patients' obstetric history matched findings in the literature $[11,16,19]$ : one patient was nulliparous and the remainder had had more than four deliveries, half of which were vaginal. It has recently been shown that normal delivery is not associated with rectocele $[16,26,27]$. As in many other case series [11, 16, 20], nearly half our patients $(48.5 \%)$ had undergone previous surgery, including six perineoplasties and seven hysterectomies (one vaginal). The role of chronic straining in the genesis of rectocele in patients constipated for over 10 years has been well documented [19, 28]. In our study, $59.37 \%$ of the patients with this condition evacuated once or twice weekly, while $8.56 \%$ evacuated two or three times a month, with a significant reduction in the average constipation score [22] from 15.23 to 4.46 postoperatively $(p=0.001)$, as reported by other authors $[8,12,14,20]$ using different stapling techniques. The average ODS score also decreased significantly from 10.63 to 2.91 ( $p=0.001)$, matching findings for other stapling techniques [11-16, 20, 29]. After surgery, patients reported little or no use of digitation, laxatives, sensation of incomplete evacuation or excessive straining. The functional continence score fell from 2.77 to $1.71(p=0.001)$, although the overall level of continence was relatively satisfactory, ranging from 0 to 7 before surgery to 0 to 4 after surgery, matching findings of a study by Gagliardi et al. [17] in which correction of rectal mucosal prolapse appears to have improved the mechanism of continence, a finding reported by Hausammann et al. as well [16]. The fact that the patients stopped using laxatives after surgery also contributed to this improvement. In this study, the sensation of fecal urgency, tenesmus and anal discomfort was considered pain, and it was moderate (5.2) on the first postoperative day and slight (1.2) on the eighth day [8, 12, 26]. Three $(8.5 \%)$ patients complained of prolonged fecal urgency and anal discomfort for 3 weeks. The level of 
satisfaction observed $(79.9,86.5,87.6$ and 88.0 at $1,3,6$ and 12 months, respectively) suggests patient approval to be similar for the TRREMS procedure and the STARR procedure $[13,29,30]$. The reduction in rectocele size from $19.23 \mathrm{~mm}$ (range 3-42 mm) to $6.68 \mathrm{~mm}$ (range 0-17 mm) at rest and from $34.89 \mathrm{~mm}$ (range $20-70 \mathrm{~mm}$ ) to $10.94 \mathrm{~mm}$ (range $0-25 \mathrm{~mm}$ ) during evacuation (both $P=0.001$ ) is similar to findings for techniques involving two staplers [8, 11-17, 29] or Contour $\operatorname{Transtar}^{\mathrm{TM}}[19,20]$. Only minor complications were observed. In three early cases $(8.57 \%)$ of moderate stenosis, mucosectomy was perceived to have been performed slightly too far from the dentate line: when the procedure was performed closer to the dentate line, no more complications occurred. Finally, it should be pointed out that while the aim of the study was not to compare the TRREMS procedure to the STARR procedure, the latter was included in the discussion as it is currently considered the gold standard for the treatment of rectocele associated with rectal prolapse and because so far very little information is available in the literature regarding the TRREMS procedure. In conclusion, the TRREMS procedure, requiring only one circular stapler, was found to be a safe and efficient technique for the treatment of rectocele associated with rectal mucosal prolapse, as shown by the significant reduction in obstructed evacuation and constipation scores and reduced levels of postoperative discomfort and complications. However, a further study should be developed enrolling more patients with longer follow-up time.

Open Access This article is distributed under the terms of the Creative Commons Attribution Noncommercial License which permits any noncommercial use, distribution, and reproduction in any medium, provided the original author(s) and source are credited.

\section{References}

1. Zbar AP, Lienemann A, Fritsch H, Beer-Gabel M, Pescatori M (2003) Rectocele: pathogenesis and surgical management. Int J Colorectal Dis 18:369-384

2. Khubchandani IT, Clancy JP 3rd, Rosen L, Riether RD, Stask JJ $\mathrm{Jr}$ (1997) Endorectal repair of rectocele revisited. Br J Surg 84:89-91

3. Richardson AC (1993) The rectovaginal septum revisited: its relationship to rectocele and its importance in rectocele repair. Clin Obstet Gynecol 36:976-983

4. Shafik A, El-Sibai O, Shafik AA, Ahmed I (2003) On the pathogenesis of rectocele: the concept of the rectovaginal pressure gradient. Int Urogynecol J 14:310-315

5. Pescatori M, Favetta U, Dedola S, Orsini S (1997) Transanal stapled excision of rectal mucosal prolapse. Tech Coloproctol 1:96-98

6. Longo A (1998) Treatment of haemorrhoidal disease by reduction of mucosa and haemorrhoidal prolapse with a circular stapling device: a new procedure. 6th world congress of endoscopic surgery. Monduzzi, Bologna, pp 777-784
7. Stuto A, Bocassanta P, Venturi M et al. (2003) Stapled transanal rectal resection (STARR) for obstructed defecation. A prospective multicentric trial. Annual meeting abstracts of American Society of colon and rectal surgeons. Dis Colon Rectum 46: A21

8. Boccasanta P, Venturi M, Salamina G, Cesana BM, Bernasconi F, Roviaro G (2004) New trends in the surgical treatment of outlet obstruction: clinical and functional results of two novel transanal stapled techniques from a randomized controlled trial. Int J Colorectal Dis 19:359-369

9. Longo A (2003) Obstructed defecation because of rectal pathologies. Novel surgical treatment: stapled transanal rectal resection (STARR). Proceedings of the 14th annual international colorectal disease symposium, Ft. Lauderdale, Florida, February 13-15

10. Corman ML, Carriero A, Hager T et al (2006) Consensus conference on the stapled transanal rectal resection (STARR) for disordered defaecation. Colorectal Dis 8:98-101

11. Boccasanta P, Venturi M, Stuto A et al (2004) Stapled transanal rectal resection for outlet obstruction: a prospective, multicenter trial. Dis Colon Rectum 47:1285-1297

12. Ommer A, Albrecht K, Wenger F, Walz MK (2006) Stapled transanal rectal resection (STARR): a new option in the treatment of obstructive defecation syndrome. Langenbecks Arch Surg 391:32-37

13. Reboa G, Gipponi M, Ligorio M, Marino P, Costantini M (2007) Stapler-assisted trans-anal surgery for the treatment of outlet obstruction syndrome. Pelviperinology 28:127-131

14. Frascio M, Stabilini C, Ricci B et al (2008) Stapled transanal rectal resection for outlet obstruction syndrome: results and follow-up. World J Surg 32:1110-1115

15. Dindo D, Weishaupt D, Lehmann K, Hetezer FH, Clavien PA, Hahnloser D (2008) Clinical and morphologic correlation after stapler transanal rectal resection for obstructed defecation syndrome. Dis Colon Rectum 51:1768-1774

16. Hausammann R, Steffen T, Weishaupt D, Beutner U, Hetzer FH (2009) Rectocele and intussusception: is there any coherence in symptoms or additional pelvic floor disorders? Tech Coloproctol. doi:10.1007/s10151-009-0454-X

17. Gagliardi G, Pescatori M, Altomare D et al (2008) Results, outcome predictors, and complications after stapled transanal rectal resection for obstructed defecation. Dis Colon Rectum 51:186-195

18. Pescatori M, Gagliardi G (2008) Postoperative complications after procedure for prolapsed hemorrhoids (PPH) and stapled transanal rectal resection (STARR) procedures. Tech Coloproctol 12:7-19

19. Renzi A, Talento P, Giardiello C, Angelone G, Izzo D, Di Sarno G (2008) Stapled trans-anal rectal resection (STARR) by a new dedicated device for the surgical treatment of obstructed defaecation syndrome caused by rectal intussusceptions and rectocele: early results of a multicenter prospective study. Int J Colorectal Dis 23:999-1005

20. Lenisa L, Schwandner O, Stuto A et al (2009) STARR with contour $^{\circledR} \operatorname{transtar}^{\mathrm{TM}}$ : prospective multicentre European study. Colorectal Dis 11:821-827

21. Regadas FSP, Regadas SM, Rodrigues LV, Misici R, Silva FR, Regadas Filho FS (2005) Transanal repair of rectocele and full rectal mucosectomy with one circular stapler: a novel surgical technique. Tech Coloproctol 9:63-66

22. Agachan F, Chen T, Pfeifer J, Reissman P, Wexner SD (1996) A constipation score system to simplify evaluation and management of constipated patients. Dis Colon Rectum 39:681-685

23. Jorge JM, Wexner SD (1993) Etiology and management of fecal incontinence. Dis Colon Rectum 36:77-97

24. Jensen MP, Karoly P, Braver S (1986) The measurement of clinical pain intensity: a comparison of six methods. Pain $27: 117-126$ 
25. Mahieu P, Pringot J, Bodart P (1984) Defecography. II. Contribution to the diagnosis of defecation disorders. Gastrointest Radiol 9:253-261

26. Soares FA, Regadas FSP, Murad-Regadas SM et al (2009) Role of age, bowel function and parity on anorectocele pathogenesis according to cinedefecography and anal manometry evaluation. Colorectal Disease 11:947-950

27. Murad-Regadas SM, Regadas FSP, Rodrigues LV et al (2009) Types of pelvic floor dysfunctions in nulliparous, vaginal delivery, and cesarean section female patients with obstructed defecation syndrome identified by echodefecography. Int J Colorectal Dis 24:1227-1232
28. Regadas FS, Murad-Regadas SM, Wexner SD et al (2007) Anorectal three-dimensional endosonography and anal manometry in assessing anterior rectocele in women: a new pathogenesis concept and the basic surgical principle. Colorectal Dis 9:80-85

29. Pechlivanides G, Tsiaoussis J, Athanasakis E et al (2007) Stapled transanal rectal resection (Starr) to reverse the anatomic disorders of pelvic floor dyssynergia. World J Surg 31:1329-1335

30. Zhang B, Ding JH, Yin SH, Zhang B, Zhao K (2010) Stapled transanal rectal resection for obstructed defecation syndrome associated with rectocele and rectal intussusception. World $\mathbf{J}$ Gastroenterol 16:2542-2548 